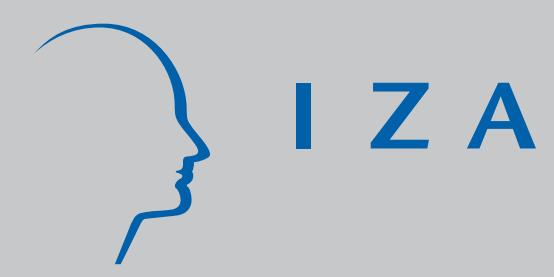

IZA DP No. 341

Testing for Asymmetry in British, German and US Unemployment Data

Stephan Kohns

August 2001 


\title{
Testing for Asymmetry in British, German and US Unemployment Data
}

\author{
Stephan Kohns \\ University of Bonn and IZA, Bonn \\ Discussion Paper No. 341 \\ August 2001
}

IZA

P.O. Box 7240

D-53072 Bonn

Germany

Tel.: +49-228-3894-0

Fax: +49-228-3894-210

Email: iza@iza.org

This Discussion Paper is issued within the framework of IZA's research area Mobility and Flexibility of Labor Markets. Any opinions expressed here are those of the author(s) and not those of the institute. Research disseminated by IZA may include views on policy, but the institute itself takes no institutional policy positions.

The Institute for the Study of Labor (IZA) in Bonn is a local and virtual international research center and a place of communication between science, politics and business. IZA is an independent, nonprofit limited liability company (Gesellschaft mit beschränkter Haftung) supported by the Deutsche Post AG. The center is associated with the University of Bonn and offers a stimulating research environment through its research networks, research support, and visitors and doctoral programs. IZA engages in (i) original and internationally competitive research in all fields of labor economics, (ii) development of policy concepts, and (iii) dissemination of research results and concepts to the interested public. The current research program deals with (1) mobility and flexibility of labor markets, (2) internationalization of labor markets and European integration, (3) the welfare state and labor markets, (4) labor markets in transition, (5) the future of work, (6) project evaluation and (7) general labor economics.

IZA Discussion Papers often represent preliminary work and are circulated to encourage discussion. Citation of such a paper should account for its provisional character. 
IZA Discussion Paper No. 341

August 2001

\section{ABSTRACT \\ Testing for Asymmetry in British, German and US Unemployment Data}

Not only the level of aggregate unemployment but also the properties of its dynamics are an important topic in macroeconomics and labor economics. Several models like e.g. matching models with endogenous job destruction explicitly predict an asymmetric pattern in the evolution of unemployment, whereas linear models with Gaussian innovations preclude such dynamics. This paper applies several tests for asymmetry to aggregate British, German and US unemployment data to assess the relevance of asymmetries and compare the testing procedures. The results indicate that unemployment increases more quickly than it decreases, which is consistent with the pattern implied by matching models with endogenous job destruction.

JEL Classification: E32, J20, J64

Keywords: Asymmetries, unemployment dynamics, matching model

Stephan Kohns

Institute of International Economics

University of Bonn

Lennéstr. 37

D-53113 Bonn

Germany

Tel.: +49 228739234

Fax: +49 228737953

Email: kohns@iiw.uni-bonn.de 


\section{Introduction}

Many studies of unemployment deal with is its level, in particular the occurrence of low unemployment in the US versus high unemployment in (continental) Europe. An important reason for this focus are the large welfare costs usually associated with persistently high unemployment. There is less emphasis on aggregate unemployment dynamics and its international differences, even though there is some microeconometric evidence for this phenomenon. ${ }^{1}$ Focussing on the dynamical properties of unemployment is a maybe more subtle point, but the welfare and policy implications are far from negligible. An asymmetric response of unemployment to expansionary or contractionary shocks has implications e.g. for the evaluation of monetary and fiscal policy: The longer it takes till the unemployment rate recovers from a contractionary shock, the more likely it is that effects like the loss of human capital or disillusionment among those unemployed set in which tend to prolong high unemployment. On the other hand, if employment reacts only sluggishly to an expansionary shock, the effect of an unanticipated money supply shock can be dampened since the resulting increase in the price level is already internalized in private expectations and nominal wage setting.

Consequently, there is also evidence of asymmetric effects of monetary and fiscal policy on aggregate output, see e.g. Kandil (2000), which may be related to behavior on the labor market (even though causality can go in both directions). Garibaldi (1997) even finds evidence of a direct link between monetary policy and flows on the labor market.

In addition, the presence of asymmetry has implications for modelling the labor market in economic theory, since e.g. the use of linear models with Gaussian innovations, which are unable to capture asymmetric dynamics, is precluded. Conversely, if no significant degree of asymmetry is found in the data, one may safely avoid the analytical complications of models like for example matching models with endogenous job destruction or models of labor demand with asymmetric adjustment costs.

Asymmetries in employment dynamics have been investigated by labor economists trying to verify implications of the dynamic theory of labor demand, see e.g. the

\footnotetext{
${ }^{1}$ In the recent years, the method of differentiating between the level and the dynamics of unemployment has been criticized for making an arbitrary distinction. Instead, the hysteresis concept has been propagated as a unifying approach for the determination of the level and the dynamics of series that should be particularly suited to the high persistence of European unemployment, see e.g. the contributions in Cross ((1995), (1988)). However, empirical evidence on full hysteresis is mixed at best, see e.g. the references in Nickell (1998).

In this study, I will leave the problem of hysteresis aside, since it is not essential for the description of the dynamical properties of unemployment series.
} 
summary in Hamermesh (1993, chap. 7) or the work by Palm and Pfann (1993), Pfann (1996) and Escribano and Pfann (1998) on labor demand in the Netherland and the UK. All these studies are 'structural' in the sense that a specific functional form, usually derived from the profit maximization problem of a firm, is imposed. Non-structural approaches to unemployment dynamics include Neftçi (1984), Falk (1986), DeLong and Summers (1986), Rothman (1991), Sichel (1993) or Ramsey and Rothman (1996). These models are non-structural in the sense that the statistics used to describe the dynamics are not related to a parameter with a specific economic interpretation like the curvature of an adjustment cost function. In addition, various nonlinear time series models have been developed to model nonlinearities of macroeconomic aggregates, e.g. threshold, STAR, ESTAR or Markov switching models. ${ }^{2}$

The aim of this paper is to investigate aggregate unemployment rates and numbers in Germany, the UK and the US for the presence of asymmetries, using several non-structural approaches. Besides allowing to compare the various methods, the use of tests imposing only very little structure on the data has the advantage of not confining oneself to a specific class of models, thereby giving a possibly more objective description of the dynamical properties of the series. The analysis may thus be seen as a starting point for a more structural approach.

The following section introduces a classification of the types of asymmetry usually discussed in the literature. Section 3 briefly discusses the occurrence of asymmetries in economic models. The main part of the paper is section 4, which presents several tests for asymmetry and applies them to the data. Section 5 concludes.

\section{A brief taxonomy of asymmetries}

Given a stationary time series $y_{t}$, the literature mentioned above considers a variety of types of asymmetry. Ramsey and Rothman (1996) argue that these different concepts can be classified along two dimensions termed transversal and longitudinal asymmetry, which are not mutually exclusive. According to this definition, a series is said to be (purely) transversally asymmetric if the asymmetry occurs in a direction orthogonal to the direction of movement of the series, see the example in figure 1 on the facing page. ${ }^{3}$ Values above the mean are less frequent but larger in absolute numbers than values below the mean (or vice versa). This

\footnotetext{
${ }^{2}$ See e.g. Tong (1990) on threshold models, Granger and Teräsvirta (1993) on STAR and ESTAR models and Hamilton (1994) on Markov switching models.

${ }^{3}$ In the case of a stationary series, the "direction of movement" is the time axis. Complications arise if the series has a deterministic or stochastic trend, but such cases will be neglected for the moment and considered later.
} 


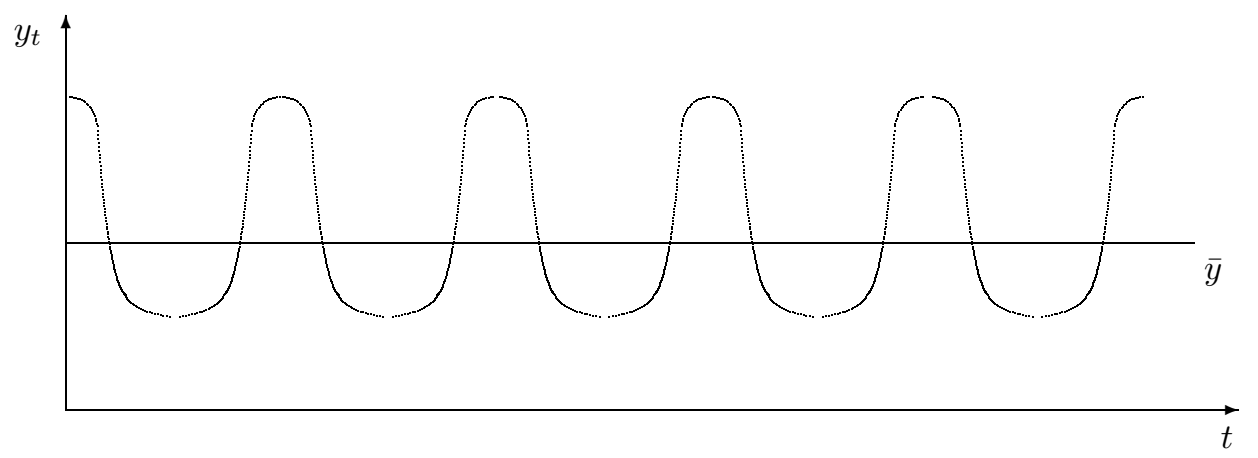

Figure 1: Example of a deep series

type of asymmetry is also called deepness.

On the other hand, a stylized longitudinally asymmetric series is asymmetric in the direction of movement of the series, see the example in figure 2. An alterna-

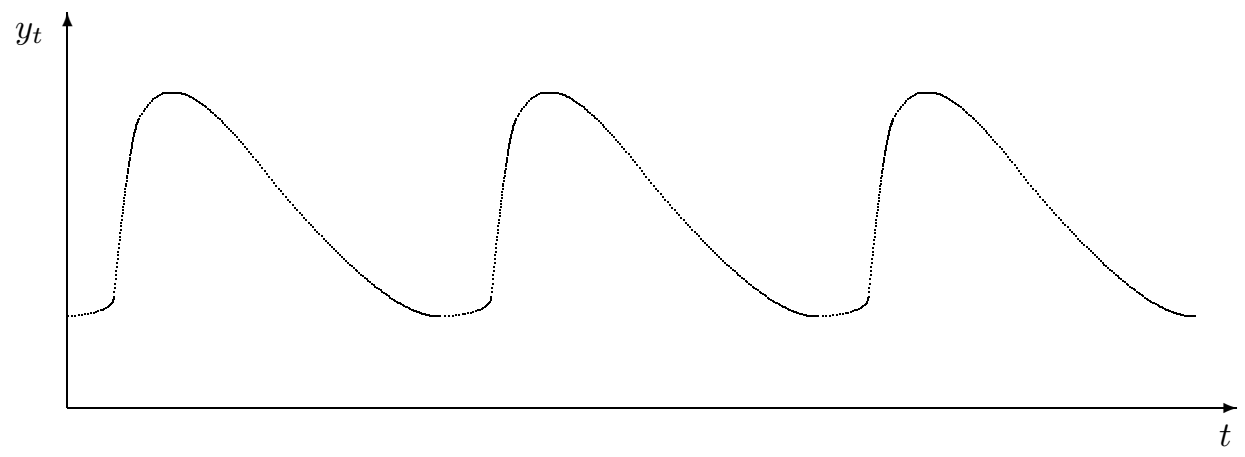

Figure 2: Example of a steep series

tive term for this pattern is steepness, since upturns are steeper than downturns or vice versa. As already said before, deepness and steepness can be present simultaneously in a time series. ${ }^{4}$

Since unemployment is counter-cyclical, deepness as in figure 1 would imply that the rise of unemployment above its equilibrium level in a recession is larger than the fall below the same level in a boom. The interpretation of steepness as in figure 2 would be that the increase of unemployment in a recession happens faster than the decrease in a boom. ${ }^{5}$

If one has been able to show that a particular time series is asymmetric, it is

\footnotetext{
${ }^{4}$ For a graphical illustration, see Sichel (1993).

${ }^{5}$ At least with respect to deepness, one might be tempted to test for asymmetry by making use of a business cycle classification like that of the NBER's Business Cycle Dating Committee. The obvious disadvantage of such an approach is the dependence of the test on the classification scheme.
} 
important for a deeper understanding and a possible explanation of the dynamics of a time series to find out the sources of the observed asymmetry. As it will become clear later, this question is particularly relevant for longitudinally asymmetric ('steep') time series. Assume that the data-generating process $x_{t}$ is a function of $p$ of its own lags, an i.i.d. innovation $\varepsilon_{t}$ and $q$ lags of $\varepsilon_{t}$, i.e. $x_{t}=f\left(x_{t-1}, x_{t-2}, \ldots, x_{t-p}, \varepsilon_{t}, \varepsilon_{t-1}, \ldots, \varepsilon_{t-q}\right)$. If $f(\cdot)$ is linear in all its arguments, we obtain an $A R M A(p, q)$ model. If, in addition, $\varepsilon_{t}$ is Gaussian, then $x_{t}$ cannot show steepness: Since it can be rewritten as a linear function of normally distributed random variables, it is normally distributed as well, so that its time path is perfectly symmetric. ${ }^{6}$ A necessary condition to obtain a longitudinally asymmetric time series is therefore that $f(\cdot)$ is nonlinear or that the innovations are not Gaussian but e.g. from a skewed distribution. ${ }^{7}$ Accordingly, two types of asymmetry can be distinguished. A steep time series is said to be type I asymmetric if the asymmetry results from a nonlinear functional form, whereas steepness that results from non-Gaussian innovations is denoted as type II asymmetry. Naturally, the two types are not mutually exclusive.

\section{Asymmetric unemployment dynamics in eco- nomic theory}

In recent years, theories of the labor market that imply asymmetric employment and unemployment dynamics have become much more prominent in the literature. This section sketches two of these approaches and the implied unemployment dynamics, namely matching models with endogenous job destruction and models of labor demand with asymmetric adjustment costs.

For the class of matching models, consider the seminal work of Mortensen and Pissarides (1994). Vacancies created by firms and unemployed workers are combined into jobs according to a matching function that serves as a shortcut for various frictions on the labor market. The productivity of a given job consists of a global and a job-specific component, and the latter is subject to repeated stochastic shocks. A job is destroyed if the job-specific productivity drops below a certain endogenously determined threshold value. The idea relevant to unemployment dynamics is that adverse shocks to aggregate job productivity raise the threshold value and therefore lead to the instantaneous destruction of all jobs with a productivity level below the new threshold. If the aggregate shock is re-

\footnotetext{
${ }^{6}$ Note that $x_{t}$ was assumed to be stationary, so that the polynomial in the lags of $x_{t}$ can be inverted.

${ }^{7}$ Still, neither condition is sufficient for the occurrence of asymmetry, see the examples in Ramsey and Rothman (1996).
} 
versed, employment recovers much more slowly since new vacancies can only be filled gradually due to the matching process. ${ }^{8}$ Hence, the matching model predicts that unemployment should show steepness with quick increases and slower decreases. ${ }^{9}$ However, the model gives no hint as to whether there should also be deepness in the series.

Figure 3 shows the stylized evolution of unemployment in a matching framework, given an unanticipated contractionary transitory shock between $t_{0}$ and $t_{1} \cdot{ }^{10}$

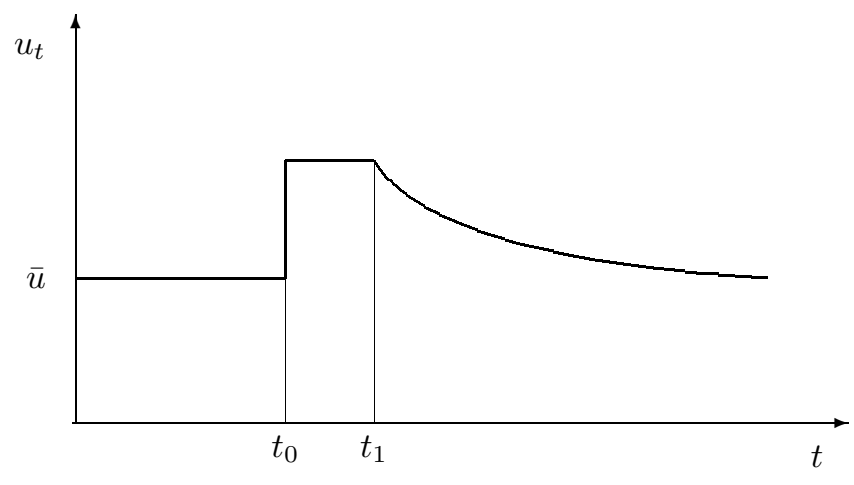

Figure 3: Dynamics of $u_{t}$ after a contractionary shock between $t_{0}$ and $t_{1}$

An alternative approach considers adjustment costs in labor demand as a source for asymmetric employment dynamics. Since the underlying causes of adjustment costs are different for increases and decreases in employment, there is no a priori reason for the cost structure to be symmetric, even though that was usually assumed in earlier studies in order to obtain closed-form solutions. Measuring adjustment costs is notoriously difficult and almost impossible in the case of implicit costs like output losses due to the need to train new workers. Further problems are the difference between net and gross adjustment, ${ }^{11}$, the dependence

\footnotetext{
${ }^{8}$ The model assumes no firing costs, but the dynamics do not change qualitatively if linear adjustment costs are added.

${ }^{9}$ The model as it is sketched here actually only implies that employment shows quick decreases and slow increases. In order to derive the pattern of unemployment mentioned in the text one has to make the additional simplifying assumption that the labor force is constant.

${ }^{10}$ In the case of an unanticipated expansionary shock, the graph looks similar, i.e. unemployment declines with decreasing speed and returns immediately to its equilibrium level $\bar{u}$ after the shock has been reversed.

Additional fluctuations in unemployment that might take place some time after a contractionary shock until the new equilibrium is reached have been neglected for simplicity, since they do not alter the main point that a large mass of jobs is destroyed at the moment the shock occurs. For details see e.g. Pissarides (2000, chp. 2.5).

${ }^{11}$ Many examples given for explicit adjustment costs (advertising, training; severance payments, legal fees) refer to gross adjustment, whereas most studies measure net adjustment costs due to lack of more appropriate data.
} 
of the type and magnitude of adjustment costs on the skill level of the workers and the appropriate form of the cost function, the relevant specifications being fixed/quasi-fixed, linear, convex or a combination of them.

Even though there is some evidence that at the micro level adjustment costs are lumpy or linear, Hamermesh (1992) shows that such cost structures can only be identified with micro data, for aggregation leads to an employment pattern that is observationally equivalent with convex costs of adjustment. Since the focus of this paper is on aggregate dynamics, an example of asymmetric convex costs of adjustment will be given. Consider the cost function for net adjustment introduced by Pfann (1990),

$$
A C\left(\Delta L_{t}\right)=e^{\beta \Delta L_{t}}-1-\beta \Delta L_{t}+\gamma\left(\Delta L_{t}\right)^{2},
$$

where $L_{t}$ is employment in period $t$ and $\gamma$ a positive parameter. This is a convenient functional form because the special case of symmetric quadratic costs that was widely used in the earlier literature is contained as a special case for $\beta=0$ and may therefore easily be tested. If $\beta>0$, hiring is more expensive than firing, so that in reaction to a transitory contractionary shock employment declines more rapidly than it recovers afterwards, and vice versa. Figure 4 depicts the stylized evolution of unemployment for this case, assuming an unanticipated contractionary transitory shock between $t_{0}$ and $t_{1}$, a Cobb-Douglas production function and net adjustment costs for labor demand that can be described by (1). As it was already the case with the matching model, there is no prediction

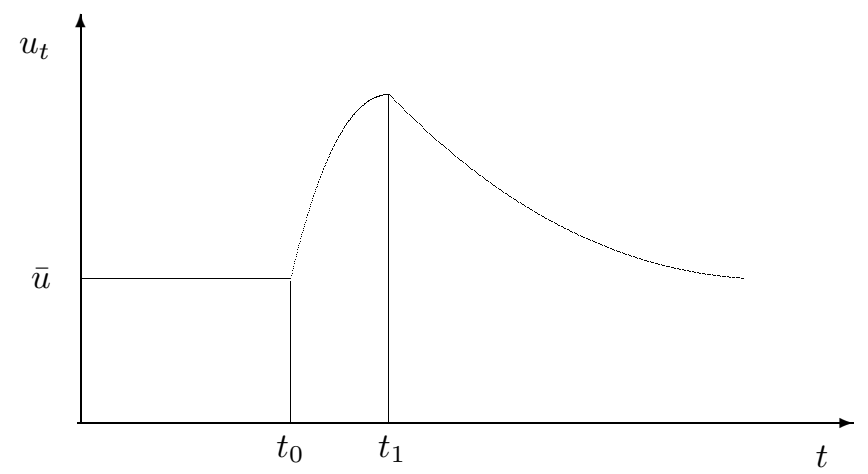

Figure 4: Dynamics of $u_{t}$ after a contractionary shock between $t_{0}$ and $t_{1}$

about the presence of deepness, let alone its direction.

The evidence on asymmetric adjustment costs in the demand for production workers is in line with the predictions of the matching model, i.e. demand for this category declines faster than it recovers. For non-production workers, results are more ambiguous, see e.g. the overview in Hamermesh (1993, chp. 7). 
The two approaches just presented explain longitudinally asymmetric dynamics as the result of an inherently asymmetric structure of the economy. Using the terminology introduced in section 2, they are examples of type I asymmetry. A pattern of unemployment dynamics as in figure 4 could also be due to asymmetric innovations, e.g. if central banks are reluctant to reduce interest rates by large amounts but do not refrain from significant rises if inflation is expected to increase. However, for labor demand in the Netherlands Palm and Pfann (1997) show that type II asymmetry can be neglected.

\section{Empirical Evidence}

This section applies several tests for asymmetry to aggregate unemployment data from West Germany, the UK and the US. Subsection 4.1 describes the data used in the analysis, and in the following subsections 4.2-4.4 the tests and the respective results are presented. ${ }^{12}$ Since the theories presented in the preceding section are rather agnostic about transversal asymmetry of unemployment, it will be particularly interesting to see whether the series are longitudinally asymmetric or 'steep'.

\subsection{Data}

The data are quarterly unemployment rates and numbers from 1969:1 to 1997:4 for West Germany, ${ }^{13}$ the UK and the US and are seasonally unadjusted except for the UK, for which raw numbers where not available. The German data were obtained from the Federal Statistical Office (Statistisches Bundesamt), the British data from the OECD Main Economic Indicators, and the US series from the Bureau of Labor Statistics. Figure 5 on the following page and figure 6 on page 9 show the unemployment rates and numbers for the three countries.

The graphs reveal pronounced seasonality in West Germany and the US. Especially for the former, the pattern of seasonality seems to change over time. In addition, the West German and British data show an upward trend. In the remainder of the paper, series UTcc denotes unemployment rates $(T=\mathrm{R})$ or numbers $(T=\mathrm{N})$ from country $c c$ with $c c=$ WG for West Germany, $c c=$ UK for the United Kingdom and $c c=$ US for the US. According to this scheme, UNUS e.g. denotes the number of unemployed in the US.

\footnotetext{
${ }^{12}$ All the calculations were performed with the WinRATS 4.3 software package.

${ }^{13}$ The analysis is restricted to West Germany, for which data where available only until 1997, since the East German data are totally dominated by the huge structural changes following reunification.
} 


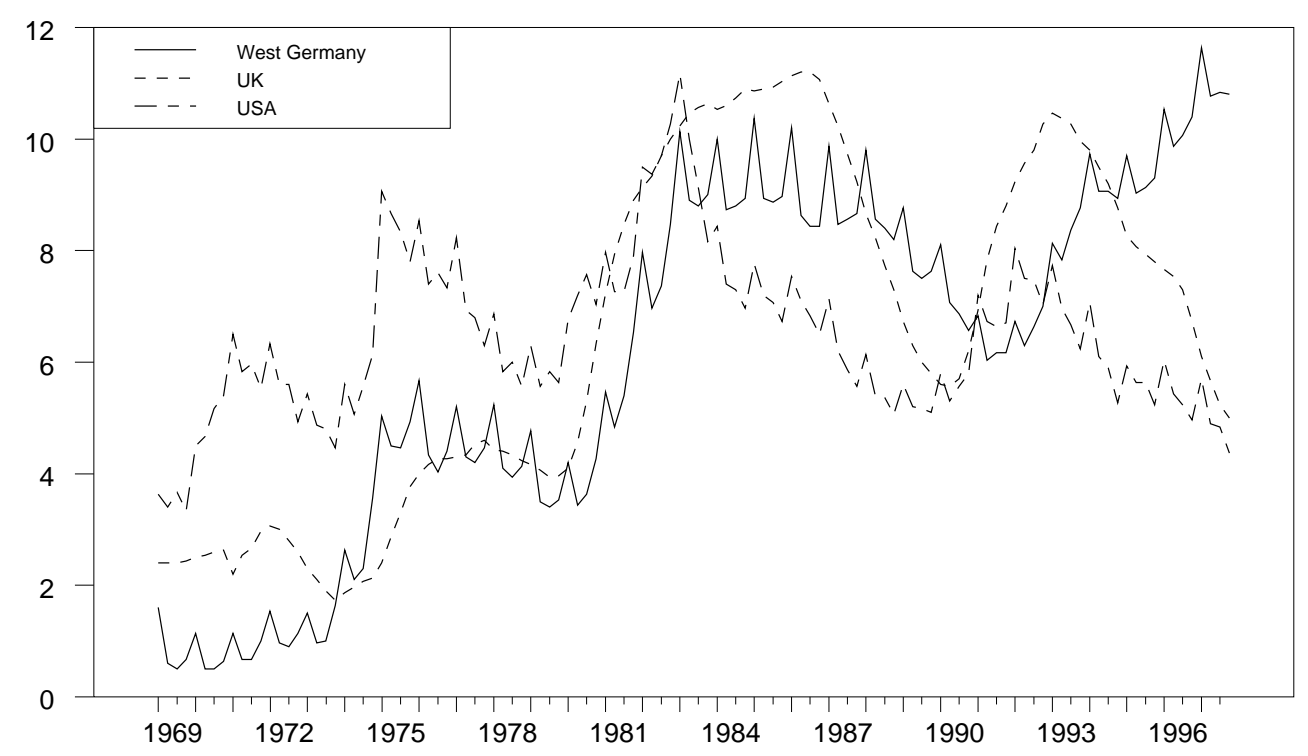

Figure 5: West German, British and US unemployment rates

Every test is applied to both unemployment rates and the number of unemployed. Both concepts are obviously equivalent if the labor force is constant, but this is not necessarily the case. Movements into and out of the labor force might depend on the business cycle, the participation rate usually increased over the last decades, and, especially in the US, immigration led to a continuously growing labor force. Consequently, graphs of the indices of the two series do not coincide, with the index based on the number of unemployed usually lying above the index of the unemployment rate. Therefore, both rates and numbers are used in the analysis. An alternative measure that is independent from changes in the labor force would be to use the number of unemployed as a fraction of the population in the working age, but the advantage of using both rates and numbers is that differences in asymmetry or the lack thereof hint at the source of asymmetry. If the pattern and extent of asymmetry is relatively similar for both measures of unemployment, asymmetry is unlikely to result from labor supply, so that a more refined structural analysis on the source of asymmetry can safely be confined to labor demand.

With respect to the frequency of the data, there is a fundamental trade-off between more information and more noise by using high-frequency like e.g. monthly data. Since not enough data points are available on an annual basis for West Germany and since asymmetry was motivated as a business cycle phenomenon so that monthly data will add little information compared to quarterly data, the latter are used in the analysis. ${ }^{14}$

\footnotetext{
${ }^{14}$ In addition, the test presented in subsection 4.2 is particularly sensitive to noise and there-
} 


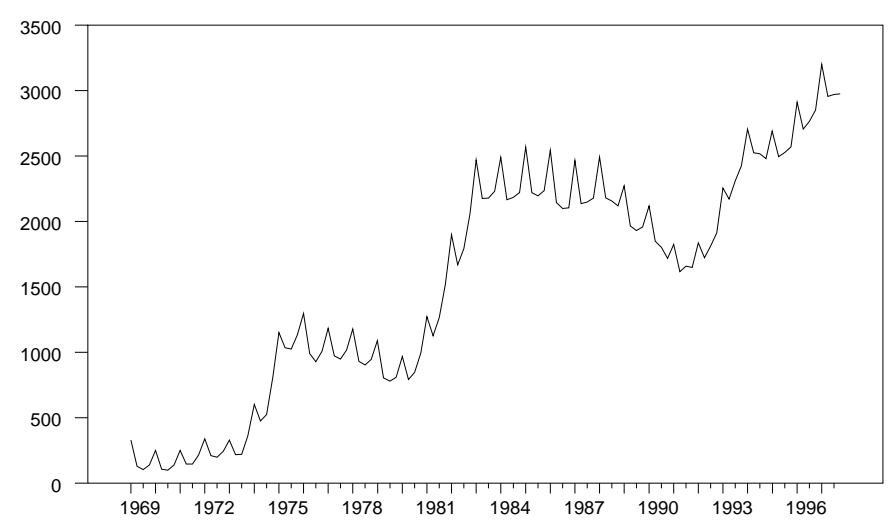

(a) West Germany

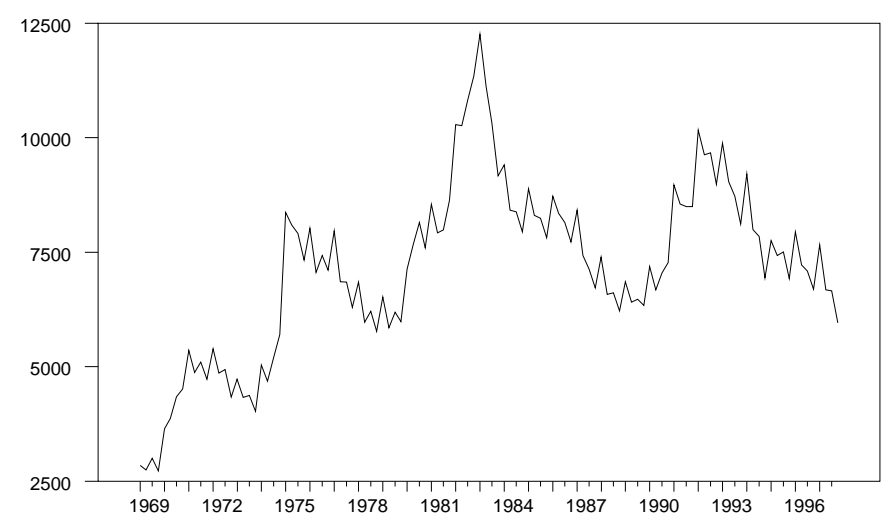

(b) USA

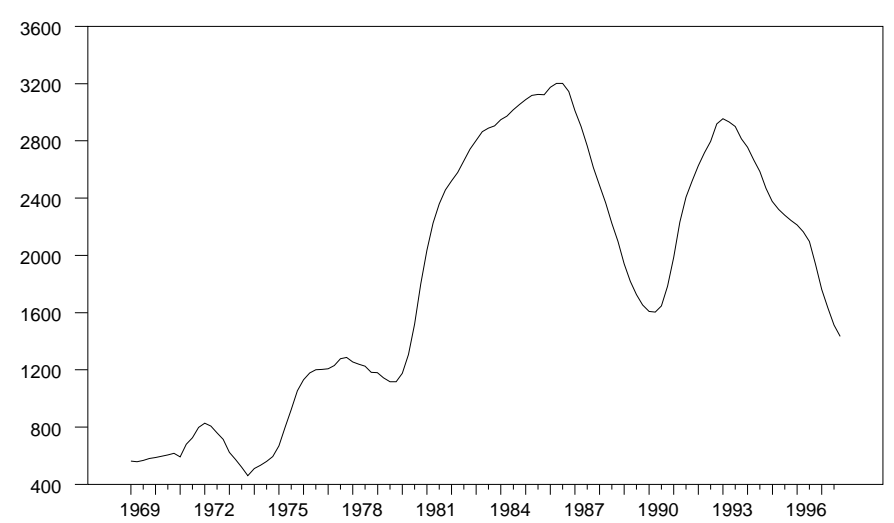

(c) United Kingdom

Figure 6: Civilian unemployment (in thousands) 
Seasonality in the data, if not properly accounted for, is likely to dominate any underlying structural asymmetries. The filters used by statistical offices for removing seasonal effects have the disadvantage of blurring the information contained in the data. Therefore, seasonal dummies (SD) are used for seasonally adjusting the US data, which seem to have a relatively stable seasonal pattern. For the West German data, showing significant changes in the magnitude of seasonality, an exponential smoothing (ES) approach is used instead.

As already noted in section 2, testing for asymmetry requires a stationary time series, but ADF-tests of the unemployment data show that, maybe except for the US, both unemployment rates and numbers are nonstationary $I(1)$-processes, see the results in table 1.

\begin{tabular}{|c|c|c|c|c|c|c|}
\hline \multirow[t]{2}{*}{ series } & \multirow[t]{2}{*}{ specification } & \multirow[t]{2}{*}{ ADF-stat. } & \multicolumn{3}{|c|}{ MacKinnon critical values } & \multirow[t]{2}{*}{$\Delta x_{t}^{S}$} \\
\hline & & & $1 \%$ & $5 \%$ & $10 \%$ & \\
\hline \multirow[t]{2}{*}{ URWG } & const.+tr. & -2.4088 & -4.0494 & -3.4535 & -3.1521 & $* * *$ \\
\hline & const. & -1.3955 & -3.4945 & -2.8895 & -2.5815 & $* * *$ \\
\hline \multirow[t]{2}{*}{ UNWG } & const.+tr. & -2.4954 & -4.0494 & -3.4535 & -3.1521 & *** \\
\hline & const. & -0.8915 & -3.4945 & -2.8895 & -2.5815 & *** \\
\hline \multirow[t]{2}{*}{ URUS } & const.+tr. & -2.6195 & -4.0494 & -3.4535 & -3.1521 & **** \\
\hline & const. & -2.6447 & -3.4945 & -2.8895 & -2.5815 & $* * *$ \\
\hline \multirow[t]{2}{*}{ UNUS } & const.+tr. & -2.3552 & -4.0414 & -3.4497 & -3.1499 & $* * *$ \\
\hline & const. & -2.6353 & -3.4889 & -2.8870 & -2.5802 & $* * *$ \\
\hline \multirow[t]{2}{*}{ URUK } & const.+tr. & -2.3453 & -4.0429 & -3.4504 & -3.1503 & $* *$ \\
\hline & constant & -2.3265 & -3.4899 & -2.8874 & -2.5804 & *** \\
\hline \multirow[t]{2}{*}{ UNUK } & const.+tr. & -1.8123 & -4.0477 & -3.4527 & -3.1516 & $* * *$ \\
\hline & const. & -2.0530 & -3.4933 & -2.8889 & -2.5812 & *** \\
\hline
\end{tabular}

Note: The lag length for each specification was chosen according to the Akaike information criterion (AIC). The critical values in columns 4-6 were computed according to the response surface in MacKinnon (1991). In the last column, rejection of the null hypothesis of a unit root in the first differences is denoted with ${ }^{* *}$ and ${ }^{* * *}$ for the $5 \%$ or $1 \%$ level, respectively.

Prior to the test, the West German and the US data were seasonally adjusted via exponential smoothing and seasonal dummies, respectively.

Table 1: ADF test of the unemployment data.

In order to transform a possibly nonstationary series $x_{t}$ into a detrended stationary series $x_{t}^{T}$, various filters can be used. The most popular are first differences, removal of a linear trend and the Hodrick-Prescott (HP) filter. ${ }^{15}$ Given that most of the series contain a stochastic trend which cannot be removed by subtracting a

fore usually inapplicable to monthly data anyway.

${ }^{15}$ The HP filter decomposes a series $y_{t}$ additively into a trend or growth component $g_{t}$ and a cyclical part $c_{t}$. This is done by minimizing the loss function $\mathcal{L}:=\sum_{t=1}^{T}\left[\left(y_{t}-g_{t}\right)^{2}+\lambda\left(\Delta^{2} g_{t}\right)^{2}\right]$. The parameter $\lambda$ determines the weight given to the smoothness of the resulting trend series, 
linear trend, first differences or the HP filter will be used in the following analysis, depending on which of the procedures is most appropriate for a particular test.

\subsection{Markov Processes}

Neftçi (1984) proposed a test for steepness based on Markov processes. The basic idea is to compare the length of increases and decreases in a series. Significant differences hint at asymmetry, since e.g. in the steep series in figure 2 decreases last much longer than increases.

To formalize this idea, $x_{t}^{S T}$, the seasonally adjusted and detrended stationary part of $x_{t}$, is condensed into an index series $I_{t}$ with

$$
I_{t}= \begin{cases}1 & \text { if } \Delta x_{t}^{S T} \geq 0 \\ 0 & \text { else }\end{cases}
$$

i.e. a series that indicates whether $x_{t}^{S T}$ increases or declines at time $t .{ }^{16}$ Assume that the evolution of $I_{t}$ can be described by a homogeneous $n$ th-order Markov process, where $n$ is going to be 1 or 2 in the following application. ${ }^{17}$ The main reason for considering only these two cases is that serious identification problems arise for larger values of $n$, since the increasing number of states makes it very likely that for some of them no observations exist.

For $n=1$, define transition probabilities $\lambda_{i}$, numbers of transitions $n_{i}$ and $\bar{n}_{i}$,

a typical value for quarterly data being 1,600 . Borderline cases are $\lambda=0$ with $g_{t}=y_{t}$ and $\lambda=\infty$ with $g_{t}=\alpha+\beta t$, i.e. a linear trend. See Hodrick and Prescott (1997).

${ }^{16}$ The test could also be modified into a test for deepness by using an index series

$$
J_{t}=\left\{\begin{array}{ll}
1 & \text { if } x_{t}^{S T} \geq \bar{x}^{S T} \\
0 & \text { else }
\end{array},\right.
$$

but this approach is not pursued here.

${ }^{17}$ The Markov property means that the probability that $I_{t}$ takes a particular value depends only on the previous $n$ realizations. A Markov process is said to be homogeneous if this probability is also time-invariant. 
state probabilities $\pi_{i, s}$ and steady-state initial probabilities $\pi_{i}, i \in 0,1$ as follows: ${ }^{18}$

$$
\begin{aligned}
\lambda_{i} & :=P\left(I_{t}=i \mid I_{t-1}=i\right) \\
n_{i} & :=\sum_{t=2}^{T} 1_{\left\{I_{t}=i \wedge I_{t-1}=i\right\}} \\
\bar{n}_{i} & :=\sum_{t=2}^{T} 1_{\left\{\neg\left(I_{t}=i\right) \wedge I_{t-1}=i\right\}} \\
\pi_{i, s} & :=P\left(I_{s}=i\right) \\
\pi_{i} & :=P\left(I_{1}=i\right), .
\end{aligned}
$$

With these definitions, the log-likelihood function for $\boldsymbol{\lambda}^{(1)}:=\left(\lambda_{1}, \lambda_{0}\right)$ given the realizations $I^{T}:=\left(I_{1}, \ldots, I_{T}\right)$ is

$$
L\left(\boldsymbol{\lambda}^{(1)} ; I^{T}\right)=\log \pi_{i}\left(\boldsymbol{\lambda}^{(1)}\right)+n_{1} \log \lambda_{1}+\bar{n}_{1} \log \left(1-\lambda_{1}\right)+n_{0} \log \lambda_{0}+\bar{n}_{1} \log \left(1-\lambda_{0}\right),
$$

where $\pi_{i}\left(\boldsymbol{\lambda}^{(1)}\right)$ is the expression appropriate for the particular sample. In order to obtain expressions for the steady-state initial probabilities $\pi_{i}, i=0,1$ note that

$$
\begin{aligned}
\pi_{1, t} & =P\left(I_{t}=1 \mid I_{t-1}=1\right) P\left(I_{t-1}=1\right)+P\left(I_{t}=1 \mid I_{t-1}=0\right) P\left(I_{t-1}=0\right) \\
& =\lambda_{1} \pi_{1, t-1}+\left(1-\lambda_{0}\right) \pi_{0, t-1} \\
\pi_{0, t} & =\left(1-\lambda_{1}\right) \pi_{1, t-1}+\lambda_{0} \pi_{0, t-1} .
\end{aligned}
$$

In a steady state, $\pi_{i, t}=\pi_{i}, i=0,1$, so that (9) and (10) collapse into the equation

$$
\left(1-\lambda_{1}\right) \pi_{1}=\left(1-\lambda_{0}\right) \pi_{0} .
$$

In addition, we must have $\pi_{1}+\pi_{0}=1$, which together with (11) yields the solutions

$$
\begin{aligned}
& \pi_{0}=\frac{1-\lambda_{1}}{2-\lambda_{0}-\lambda_{1}} \\
& \pi_{1}=\frac{1-\lambda_{0}}{2-\lambda_{0}-\lambda_{1}} .
\end{aligned}
$$

After plugging (12) and (13) into (8), the log-likelihood function can be maximized with respect to $\boldsymbol{\lambda}^{(1)}$, which yields estimated transition probabilities $\hat{\lambda}_{1}$ and $\hat{\lambda}_{0}$ and the respective standard errors. ${ }^{19} \mathrm{~A}$ similar approach can be chosen if a

\footnotetext{
${ }^{18}$ The difference between $\pi_{i, s}$ and $\pi_{i}$ is that the latter apply to the steady state, i.e. given an arbitrary starting point, the $\pi_{i}$ are the probabilities to which the economy converges when it is not hit by any further shocks.

${ }^{19}$ Note that in the absence of the initial conditions, the ML-estimates are simply the respective shares, i.e. $\frac{n_{i}}{n_{i}+\bar{n}_{i}}, i=0,1$.
} 
second order homogeneous Markov process is assumed $(n=2)$. The necessary steps to obtain estimates for $\boldsymbol{\lambda}^{(2)}:=\left(\lambda_{11}, \lambda_{00}, \lambda_{10}, \lambda_{01}\right)$ are, even though a bit more tedious, totally analogous to the case of $n=1$ and are spelled out in the appendix.

Based on these estimates, the series $x_{t}$ is said to be longitudinally asymmetric if $\hat{\lambda}_{1}$ and $\hat{\lambda}_{0}$ are statistically different, because in this case the average durations of increases and decreases are also different. If for example $\hat{\lambda}_{1}$ is significantly smaller than $\hat{\lambda}_{0}$ or $\hat{\lambda}_{11}$ significantly smaller than $\hat{\lambda}_{00}$ in the case of $n=2$, increases happen on average more quickly than decreases, and vice versa. Note that the stylized evolution of unemployment in figure 3 would even imply $\lambda_{1}=\lambda_{11}=0$. The appropriate testing procedure for these hypotheses is a likelihood-ratio test, and the test statistic is distributed $\chi^{2}$ with one degree of freedom.

A LR test may also be applied to differentiate between the first and the second order specification, but in this case one has to assume that the initial states are deterministic, i.e. the terms with the initial probabilities $\pi_{i}$ are dropped from (8) and the corresponding equation for the second order Markov process, see Anderson and Goodman (1997). Under the hypothesis that both processes fit the data equally well the test statistic is distributed $\chi^{2}$ with two degrees of freedom.

The positive trend that is observed in some of the series is an obvious problem. Since increases occur more often in such a case, the estimates of $\lambda_{1}$ and $\lambda_{11}$ are biased upward. Even if the true pattern in the cyclical component implied $\lambda_{1}<\lambda_{0}$ (or $\lambda_{11}<\lambda_{00}$ ), we would still accept the null hypothesis too often. Therefore, the series have been detrended with the HP filter except for the US data, for which also undetrended data have been used. Using first differences instead of the HP filter (which would mean not to detrend the series at all prior to the actual test given that $I_{t}$ is aldready defined via the first differences of $x_{t}$ ) would not remove the bias. In the presence of an upward trend in $x_{t}$, the first differences have a positive mean, so that probably still too many increases would be measured.

Results for a first order and a second order process are given in table 2 on the next page. Except for three specifications - the first and second order processes for the German number of unemployed and the second order process for the HPfiltered US number of unemployed -, the estimates of the $\lambda_{1}$ and $\lambda_{11}$ are always smaller than those of the $\lambda_{0}$ and $\lambda_{00}$ as predicted by the matching model, and in all but one cases the difference is highly significant. Contrary to the stylized evolution of the matching model, though, the estimates $\hat{\lambda}_{1}$ and $\hat{\lambda}_{11}$ are also significantly different from zero. For all series, the specifications based on a first order Markov process is strongly rejected in favor of a second order process. The transition probabilities in the US are significantly lower than in West Germany or the UK, which means that the respective states are less persistent in the US. 


\begin{tabular}{|c|c|c|c|c|c|c|c|c|}
\hline \multirow[t]{2}{*}{ series } & \multirow[t]{2}{*}{$\operatorname{adj}^{a}$} & \multicolumn{3}{|c|}{ 1st order process } & \multicolumn{3}{|c|}{ 2nd order process } & \multirow[t]{2}{*}{ model $^{\mathrm{c}}$} \\
\hline & & $\hat{\lambda}_{1}$ & $\hat{\lambda}_{0}$ & $p$-value ${ }^{\mathrm{b}}$ & $\hat{\lambda}_{11}$ & $\hat{\lambda}_{00}$ & $p$-value ${ }^{\mathrm{b}}$ & \\
\hline URWG & $\mathrm{HP} / \mathrm{ES}$ & $\begin{array}{l}0.738 \\
(0.000)\end{array}$ & $\begin{array}{l}0.849 \\
(0.000)\end{array}$ & 0.000 & $\begin{array}{l}0.806 \\
(0.000)\end{array}$ & $\begin{array}{l}0.854 \\
(0.000)\end{array}$ & 0.000 & 0.000 \\
\hline UNWG & $\mathrm{HP} / \mathrm{ES}$ & $\begin{array}{l}0.790 \\
(0.000)\end{array}$ & $\begin{array}{l}0.728 \\
(0.000)\end{array}$ & 0.000 & $\begin{array}{l}0.833 \\
(0.000)\end{array}$ & $\begin{array}{c}0.708 \\
(0.000)\end{array}$ & 0.000 & 0.000 \\
\hline \multirow[t]{2}{*}{ URUS } & & $\begin{array}{l}0.566 \\
(0.000)\end{array}$ & $\begin{array}{l}0.666 \\
(0.000)\end{array}$ & 0.000 & $\begin{array}{l}0.697 \\
(0.000)\end{array}$ & $\begin{array}{l}0.715 \\
(0.000)\end{array}$ & 0.087 & 0.000 \\
\hline & $-/ \mathrm{SD}$ & $\begin{array}{l}0.586 \\
(0.000)\end{array}$ & $\begin{array}{l}0.733 \\
(0.000)\end{array}$ & 0.000 & $\begin{array}{l}0.713 \\
(0.000)\end{array}$ & $\begin{array}{l}0.773 \\
(0.000)\end{array}$ & 0.000 & 0.000 \\
\hline \multirow[t]{2}{*}{ UNUS } & & $\begin{array}{l}0.591 \\
(0.000)\end{array}$ & $\begin{array}{l}0.650 \\
(0.000)\end{array}$ & 0.000 & $\begin{array}{l}0.661 \\
(0.000)\end{array}$ & $\begin{array}{l}0.644 \\
(0.000)\end{array}$ & 0.123 & 0.000 \\
\hline & $-/ \mathrm{SD}$ & $\begin{array}{l}0.642 \\
(0.000)\end{array}$ & $\begin{array}{l}0.672 \\
(0.000)\end{array}$ & 0.000 & $\begin{array}{l}0.641 \\
(0.000)\end{array}$ & $\begin{array}{l}0.686 \\
(0.000)\end{array}$ & 0.000 & 0.002 \\
\hline URUK & $\mathrm{HP} /-$ & $\begin{array}{l}0.767 \\
(0.000)\end{array}$ & $\begin{array}{l}0.793 \\
(0.000)\end{array}$ & 0.000 & $\begin{array}{l}0.749 \\
(0.000)\end{array}$ & $\begin{array}{c}0.822 \\
(0.000)\end{array}$ & 0.000 & 0.000 \\
\hline UNUK & $\mathrm{HP} /-$ & $\begin{array}{l}0.811 \\
(0.000)\end{array}$ & $\begin{array}{l}0.837 \\
(0.000)\end{array}$ & 0.000 & $\begin{array}{l}0.815 \\
(0.000)\end{array}$ & $\begin{array}{l}0.846 \\
(0.000)\end{array}$ & 0.000 & 0.000 \\
\hline
\end{tabular}

Note: $p$-values of the estimates are given in parentheses.

a Type of adjustment: HP denotes the HP-filter for the removal of a stochastic trend; ES and SD denote the type of seasonal adjustment, i.e. exponential smoothing or seasonal dummies, respectively.

b Result of a LR-test for symmetry. Under the null, the test statistic is $\chi^{2}$-distributed with one degree of freedom.

c Result of a LR-test for a 1st order versus a 2nd order Markov process. The $p$-value is based on estimates that ignore the initial conditions, see the explanation given in the text. Under the null, the test statistic is $\chi^{2}$-distributed with two degrees of freedom.

Table 2: Results of Neftçi's test for asymmetry, using 1st and 2nd order Markov processes

Finally, except for the somewhat anomalous case of West Germany, the transition probabilities for the number of unemployed are higher than for the unemployment rates, i.e. the number of unemployed reacts a bit more persistently.

\subsection{Skewness of levels and first differences}

DeLong and Summers (1986) use a different approach to test for steepness. Instead of simply comparing the durations of increases and decreases, they also focus on the magnitude of the changes. The basic idea of their test is that if a series is steep with quick increases and relatively slow decreases as in figure 2, increases per unit of time are on average larger than decreases, but occur less frequently. This implies that the distribution of the changes in $x_{t}^{S T}$ is skewed to the right as in figure 7 on the facing page.

Similarly, for a series showing deepness with high, but less frequent spikes, positive deviations from the mean are on average larger but less frequent than negative 


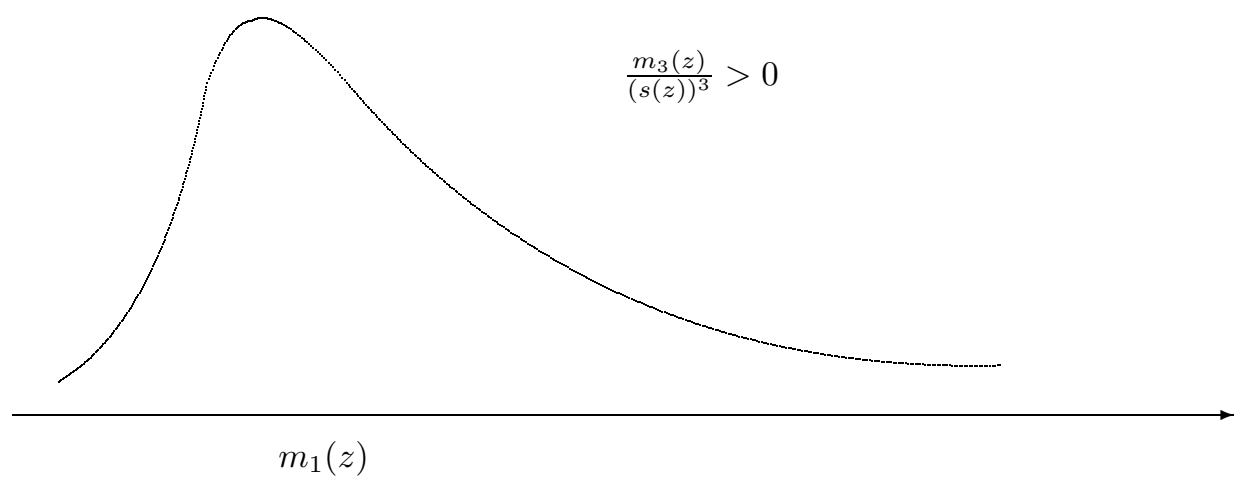

Figure 7: Density function of a random variable $z$ that is skewed to the right

deviations, so that in this case the distribution of the levels of $x_{t}^{S T}$ is skewed to the right, too.

A natural choice for a test statistic that captures the degree of asymmetry in the distribution of a random variable $z$ is the coefficient of skewness $s k(z)$. It is defined as the normalized centered third moment, i.e. $\operatorname{sk}(z):=\frac{m_{3}(z)}{(\sigma(z))^{3}}$, where $m_{3}(z)$ and $\sigma(z)$ denote the centered third moment $E\left[(z-E(z))^{3}\right]$ and the standard deviation of $z$, respectively. Evidently, one obtains $s k(z)=0$ if the distribution of $z$ is symmetric.

In order to test the hypotheses $s k\left(x_{t}^{S T}\right)=0$ or $s k\left(\Delta x_{t}^{S T}\right)=0$, the respective standard deviations are needed. For a stationary iid-process with sample size $T$, the variance of the skewness is $\frac{6}{T}$, but this formula is obviously inapplicable due to the high degree of serial correlation in $x_{t}$. Two methods are chosen to obtain valid standard errors. For the first, an $A R M A$-model is fitted to the series to be investigated. ${ }^{20}$ Then, this model is repeatedly simulated with Gaussian innovations. The coefficients of skewness of the simulated series can then be used to compute the required standard deviation. The second method is a bootstrap procedure, i.e. artificial series are created by randomly drawing entries from the original series. The coefficients of skewness of these artificial series also yield an estimate of $\sigma(\widehat{s k}(\cdot))$.

The matching-model implies $s k\left(\Delta x_{t}^{S T}\right)>0$. The coefficient of skewness is computed from centered moments, so that a possible nonnegative drift in the series will not not affect the results. Therefore, both the seasonally adjusted first differences $\Delta x_{t}^{S}$ as well as $\Delta x_{t}^{S T}$, the seasonally adjusted first differences of the detrended levels, are a valid basis for the test. Columns three and four of table

\footnotetext{
${ }^{20}$ From the set of possible specifications, a model was chosen such that it minimizes the AIC given that the residuals are still uncorrelated.
} 
3 show the estimated coefficients of skewness for both types of first differences. All the estimates have the expected positive sign. They are always significant

\begin{tabular}{|l|c|c|c|c|}
\hline series & adj. $^{\mathrm{a}}$ & $\Delta x_{t}^{S} \mathrm{~b}$ & $\Delta x_{t}^{S T} \mathrm{~b}$ & $x_{t}^{S T} \mathrm{~b}$ \\
\hline URWG & $\mathrm{HP} / \mathrm{ES}$ & $\begin{array}{c}0.673 \\
(0.044 / 0.000)\end{array}$ & $\begin{array}{c}0.610 \\
(0.042 / 0.003)\end{array}$ & $\begin{array}{c}-0.117 \\
(0.743 / 0.509)\end{array}$ \\
\hline UNWG & $\mathrm{HP} / \mathrm{ES}$ & $\begin{array}{c}0.623 \\
(0.056 / 0.001)\end{array}$ & $\begin{array}{c}0.527 \\
(0.082 / 0.003)\end{array}$ & $\begin{array}{c}0.051 \\
(0.881 / 0.776)\end{array}$ \\
\hline URUS & $\mathrm{HP} / \mathrm{SD}$ & $\begin{array}{c}1.566 \\
(0.000 / 0.017)\end{array}$ & $\begin{array}{c}1.606 \\
(0.000 / 0.034)\end{array}$ & $\begin{array}{c}0.720 \\
(0.040 / 0.000)\end{array}$ \\
\hline UNUS & $\mathrm{HP} / \mathrm{SD}$ & $\begin{array}{c}1.075 \\
(0.000 / 0.008)\end{array}$ & $\begin{array}{c}1.056 \\
(0.000 / 0.021)\end{array}$ & $\begin{array}{c}0.778 \\
(0.032 / 0.000)\end{array}$ \\
\hline URUK & $\mathrm{HP} /-$ & 0.473 & 0.766 & -0.756 \\
& & $(0.181 / 0.014)$ & $(0.012 / 0.000)$ & $(0.062 / 0.000)$ \\
\hline UNUK & $\mathrm{HP} /-$ & 0.419 & 0.839 & -0.765 \\
& & $(0.284 / 0.024)$ & $(0.008 / 0.000)$ & $(0.018 / 0.000)$ \\
\hline
\end{tabular}

a Type of adjustment: HP denotes the HP-filter for the removal of a stochastic trend; ES and SD denote the type of seasonal adjustment, i.e. exponential smoothing or seasonal dummies, respectively.

b $p$-values are given in parentheses. The first value refers to standard errors derived from the simulation of an ARMA-model, whereas the second is based on standard errors obtained via a bootstrap procedure.

Table 3: First differences and levels for Germany, United States and United Kingdom

according to the bootstrap based $p$-values and in most cases also according to the $A R M A$-simulation based $p$-values. The skewness test therefore confirms the results from the previous subsection. The choice of $\Delta x_{t}^{S}$ versus $\Delta x_{t}^{S T}$ does not matter much in the case of West Germany or the US, but the estimates for the UK almost double if $\Delta x_{t}^{S T}$ is chosen instead of $\Delta x_{t}^{S}$. Finally, judging from the size of the coefficients and their significance, evidence of steepness is strongest in the US.

The last column in table 3 gives the estimated coefficients of skewness for the detrended levels $x_{t}^{S T}$. One might expect unemployment to be particularly high during recessions so that the estimates should be significantly positive, but this result is found only for the US. The estimates for West Germany are insignificantly different from 0, and the British data even suggest the opposite pattern, i.e. unemployment declines to particularly low levels during booms. ${ }^{21}$

\footnotetext{
${ }^{21}$ Looking at the graphs of the British unemployment data in figures 5 and 6 , a possible explanation for this result is the pronounced trough in the second half of the eighties. The large negative deviations from the estimated trend in this period probably dominate the distribution of $x_{t}^{S T}$.
} 


\subsection{Time reversibility test}

The time reversibility (TR) test was proposed by Ramsey and Rothman (1996). As the name 'time reversibility' already suggests, this test checks for a certain type of symmetry along the time axis. Consider the stylized deep and steep series in figures 1 and 2. The first series is axially symmetric with respect to an axis orthogonal to the time axis, i.e. reversing the time axis would leave the dynamics of the series unchanged. The steep series in the second graph, on the other hand, does not possess this property, since reversing the time axis would lead to a different pattern with slow increases and quick decreases, instead of quick increases and slow decreases in the original series. Hence, the series in figure 1 , even though it is transversally asymmetric, is time reversible, whereas the the longitudinally asymmetric series in the second figure is not. The time reversibility test therefore is a test for steepness, but it may be shown that by applying it to the first differences of a series it can also be used to test for deepness. To make the somewhat heuristic concept of reversing the time axis more precise, consider the following definition of time reversibility (compare Ramsey and Rothman (1996)):

Definition 1. A process $z_{t}$ is said to be time reversible if for every positive integer $n$, every $t_{1}, t_{2}, \ldots, t_{n} \in \mathbb{R}$ and all $m \in \mathbb{Z}$ the vectors $\left(z_{t_{1}}, z_{t_{2}}, \ldots, z_{t_{n}}\right)$ and $\left(z_{-t_{1}+m}, z_{-t_{2}+m}, \ldots, z_{-t_{n}+m}\right)$ have the same joint probability distribution.

According to this definition, an i.i.d.-process is obviously time reversible. Furthermore, time reversibility can be shown to imply stationarity, so that the test requires a stationary series in order to obtain a meaningful result. ${ }^{22}$

For the test itself, a more manageable criterion for time reversibility is needed. The following theorem gives a necessary condition for time reversibility.

Theorem. Let $z_{t}$ be a stationary mean-zero process and let the joint distribution of $\left(z_{t}, z_{t-k}\right)$ and $\left(z_{t-k}, z_{t}\right)$ be uniquely determined by the moments and crossmoments of $z_{t}$ and $z_{t-k}$. Then $z_{t}$ is time reversible only if

$$
\begin{aligned}
E\left(z_{t}^{i} z_{t-k}^{j}\right) & =E\left(z_{t}^{j} z_{t-k}^{i}\right) \\
\Leftrightarrow \quad \gamma_{i, j} & :=E\left(z_{t}^{i} z_{t-k}^{j}\right)-E\left(z_{t}^{j} z_{t-k}^{i}\right)=0
\end{aligned}
$$

$\forall i, j, k \in \mathbb{N}$.

For the empirical implementation, it is impossible to consider all possible combinations of $i, j$ and $k$. Therefore, a narrower definition of time reversibility is needed.

\footnotetext{
${ }^{22}$ I.e. with a nonstationary series, one would always reject the null hypothesis of time reversibility.
} 
Definition 2. A stationary mean-zero process is said to be time reversible to order $m$ and degree $K$ if condition (14) holds for all $i, j, k \in \mathbb{N}$ with $i+j \leq m$ and $k \leq K$.

Ramsey and Rothman (1996) note that a value of $m=3$ is usually sufficient to detect time irreversibility. ${ }^{23}$ A suitable estimator for (15) in the case of $i=2$ and $j=1$ is the sample equivalent of (15),

$$
\begin{aligned}
\hat{\gamma}_{21}(k) & :=\frac{1}{T-k} \sum_{t=k+1}^{T}\left(z_{t}^{2} z_{t-k}-z_{t} z_{t-k}^{2}\right) \\
& =\frac{1}{T-k} \sum_{t=k+1}^{T} z_{t} z_{t-k}\left(z_{t}-z_{t-k}\right) .
\end{aligned}
$$

Since (14) is a necessary condition for a series to be time reversible, $\hat{\gamma}_{21}(k)$ should be insignificantly different from zero $\forall k \leq K$, i.e. if the condition is not fulfilled for some $k$, this is sufficient for the presence of time irreversibility. In addition, the sign of $\hat{\gamma}_{21}(k)$ gives some information on the shape of the series. Through simulations it may be shown that a pattern with slow increases and quick decreases leads to positive estimates of $\hat{\gamma}_{21}(k)$ for small values of $k$, whereas for a pattern with quick increases and small decreases as in figure 2 one obtains negative values of $\hat{\gamma}_{21}(k)$ for small values of $k$.

As noted above, a purely transversally asymmetric series is time reversible, and therefore the estimates $\hat{\gamma}_{21}(k)$ are insignificantly different from zero. However, the time derivative of a 'deep' series is longitudinally asymmetric. Specifically, a series with high peaks as in figure 1 has a derivative with slow increases and quick decreases, so that the $\hat{\gamma}_{21}(k)$ s of the first differences as a proxy for the time derivative should be positive. The opposite applies to a deep series with deep troughs, i.e. the $\hat{\gamma}_{21}(k) \mathrm{s}$ of the first differences should be negative. Hence, for a given stationary series $z_{t}$ applying the TR test to the levels yields information on the degree of steepness, and applying it to the first differences captures the degree of deepness. ${ }^{24}$

In order to make statistical inferences, standard errors for the estimated $\hat{\gamma}_{21}(k) \mathrm{s}$ are needed. If $z_{t}$ is a mean-zero i.i.d. process with finite fourth moments $m_{4}$, third moments $m_{3}$ and variance $\sigma^{2}$, it can be shown that

$$
\operatorname{var}\left(\hat{\gamma}_{21}(k)\right)=\frac{2}{T-k}\left(m_{4} \sigma^{2}-m_{3}^{2}-\frac{T-2 k}{T-k} \sigma^{6}\right) .
$$

\footnotetext{
${ }^{23}$ Suitable values for $K$ will be considered below. The value $m=3$ is the smallest possible value. For $m=2, E\left(z_{t}^{i} z_{t-k}^{j}\right)$ equals the covariance function, which is symmetric so that (14) is always fulfilled.

${ }^{24}$ Insofar the methodology is exactly opposite to the skewness test, where the first differences of a series have to be analyzed in order to detect steepness and the levels yields information on deepness.
} 
For the empirical implementation, the respective moments can be replaced by their sample analogues, but as in the case of the skewness test, this formula is not applicable for the unemployment data due to the presence of serial correlation. Therefore, for every series an appropriate $A R M A$-model is simulated to yield a large number of estimates for $\hat{\gamma}_{21}(k)$, from which a standard error for the bicovariance function of the original series can be computed. ${ }^{25}$ Since the test is performed for various lags $k$, it becomes more likely to get a significant test statistic $\widehat{\operatorname{tr}}(k):=\hat{\gamma}_{21}(k) / \widehat{\operatorname{var}}\left(\hat{\gamma}_{21}(k)\right)$ even if the null hypothesis of time reversibility is true. Therefore, an additional test statistic, namely the $p$-value of the largest $\widehat{t r}(k)$ (denoted $p$-max value) is reported. ${ }^{26}$ This number gives the probability of getting a value for the TR test statistic that is larger in absolute numbers than the largest of the $K$ estimates $|\widehat{t r}(k)|$ from the original series. The $p$-max value usually increases with $K$, the number of lags considered in the test, and is thus a rough measure of the joint significance of the individual $\hat{\gamma}_{21}(k)$ s. It can be obtained as a byproduct of the simulation.

Finally, given that time reversibility is rejected for the original series, the TR test can also be used to obtain information on the source of asymmetry. In section 2, type I and type II asymmetry were introduced as possible types of steepness, depending on whether asymmetry was due to the functional form or asymmetric innovations of the data generating process. If the TR test applied to the residuals fails to reject the null hypothesis of time reversibility, the asymmetry in the original series is due to non-Gaussian i.i.d. innovations. If, on the other hand, the residuals are time irreversible as well, the asymmetry in the original series is due to the functional form of the original series. ${ }^{27}$

For the empirical analysis, the maximum lag length $K$ is set equal to 8 and 12 . This choice is meant to be a compromise between the power of the test and the degrees of freedom on the one hand and the minimum time span necessary to capture business cycle phenomena on the other. As before, the series are detrended and, when necessary, seasonally adjusted before the actual test. Contrary to Ramsey and Rothman (1996) who use first differences to make the series stationary, the HP filter is used in this analysis since the use of first differences would preclude making inferences about asymmetry in the levels.

Table 4 on the next page shows the results for the detrended levels. The upper panel contains the statistics $\widehat{\operatorname{tr}}(k)$ for lags 1 to 8 as well as the $p$-max values for 8 and 12 lags. The lower panel contains the respective numbers for the residuals of

\footnotetext{
${ }^{25}$ The same $A R M A$-specifications were chosen as in the previous section.

${ }^{26}$ See Ramsey and Rothman (1996) or Richardson (1993).

${ }^{27}$ Even though Ramsey and Rothman (1996, p. 12) are a bit vague in explaining why one should find time irreversibility in the residuals if steepness in the original series is due to the functional form, I still use their methodology to differentiate between the two sources of time irreversibility.
} 


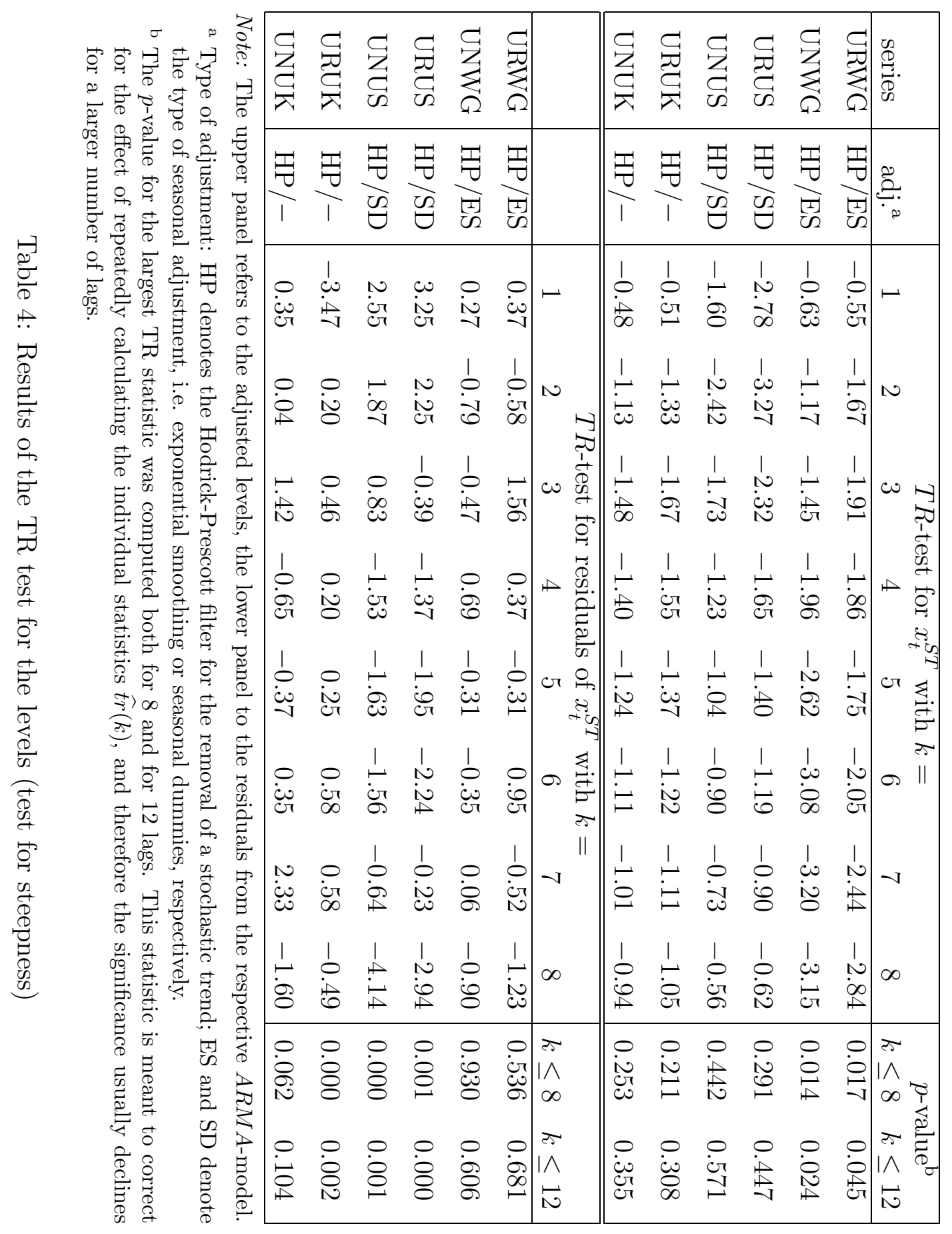


$A R M A$-models for the levels. Table 5 on the following page reports the results of the same analysis performed on the adjusted first differences, i.e. the test for deepness.

The results in table 4 are broadly consistent with those from the Markov-process test and the skewness test of the first differences in the previous subsections. Recall that steepness of the type displayed in figure 2 implies $\hat{\gamma}_{21}(k)<0$. For all of the levels, the $\widehat{\operatorname{tr}}(k) \mathrm{s}$ are numerically negative, and for each of the West German and US series several of them are individually significant. It should be noted, however, that the $p$-max values are insignificant for the US series, even though the estimates $\hat{\gamma}_{21}(k)$ are individually highly significant for small lags $k$. The evidence of steepness is weakest in the UK, where none of the $\hat{\gamma}_{21}(k) \mathrm{s}$ is significant, but all are numerically negative. With respect to the source of asymmetry, the lower panel suggests type II asymmetry in West Germany versus type I asymmetry in the US. The results for the British data are somewhat contradictory, since the $p$-max value for the residuals is significant even though no asymmetry was found in the first stage of the analysis.

Looking at the results in table 5 and comparing them to those in the last column of table 3, one can see that the conclusions from the skewness test of the levels are confirmed. The purported pattern of relatively high peaks in unemployment, which should be reflected in positive estimates $\hat{\gamma}_{21}(k)$ of the first differences, is found significantly in the US and insignificantly in West Germany. For the British data, one obtains negative estimates that suggest the opposite pattern, but as already noted in the previous section, this result may be due to the pronounced trough in the second half of the eighties. As regards the source of asymmetry, the lower panel suggests type I asymmetry in the US. For West Germany and the UK, the results in the lower panel don't quite fit those in the upper panel where no or only weak evidence of deepness was found. Finally, except for the levels in the UK, there is no discernible difference between the results for the unemployment rates and the number of employed..

\section{Conclusions}

The non-structural tests for asymmetry used in this paper yield rather strong and consistent evidence of steepness in West German, British and US unemployment data. The observed pattern of quick increases and relatively slow decreases fits the predictions of matching models with endogenous job destruction as well as of models of labor demand with asymmetric adjustment costs if costs of hiring are relatively higher. It should be clear, though, that the results are certainly not a formal test of these models.

Furthermore, there is some evidence on pronounced unemployment spikes during 


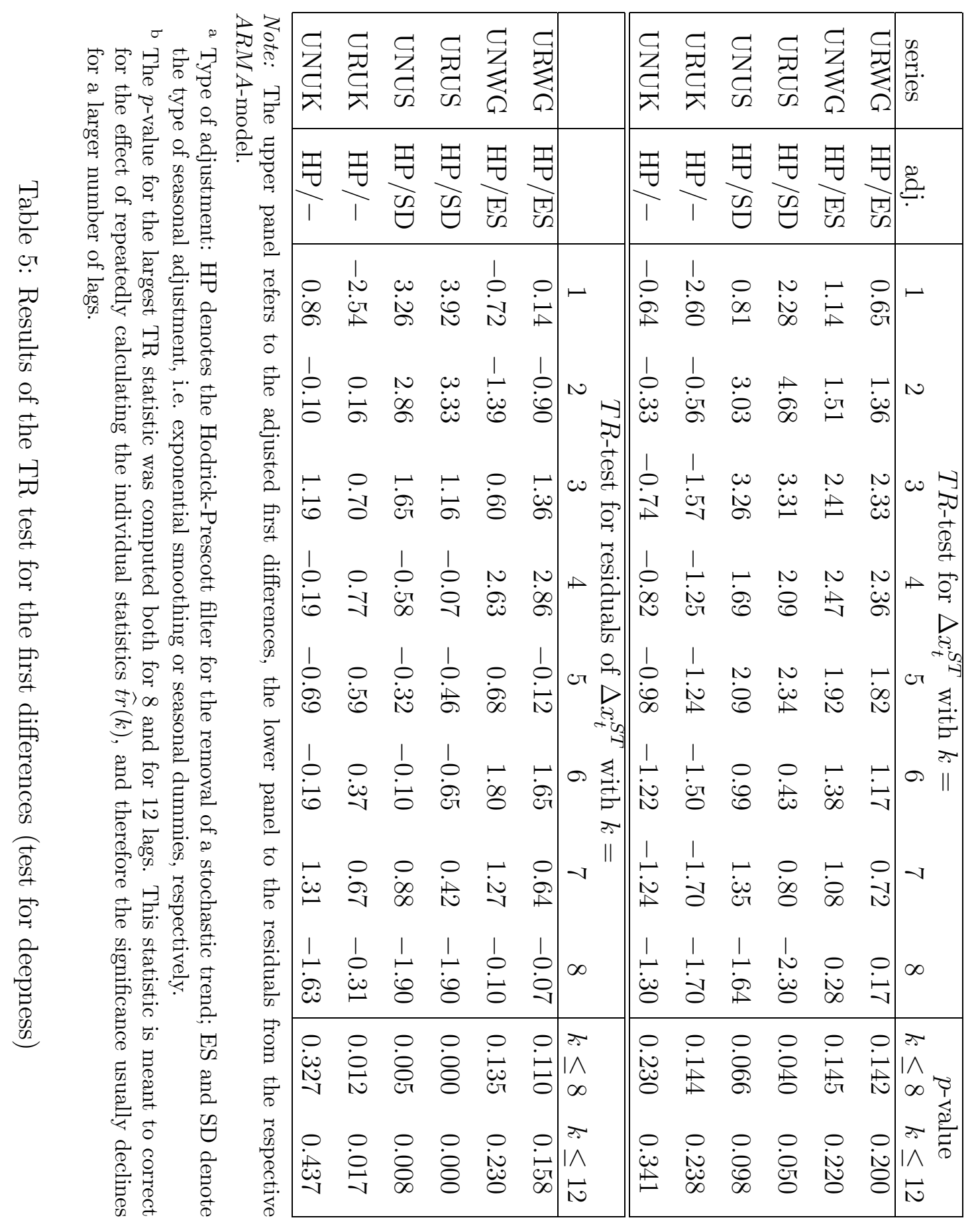


recessions in the US. Since the results do not differ much between unemployment rates and numbers, there is reason to believe that the asymmetric behavior is not mainly due to labor supply or movements into and out of the labor force but rather to labor demand or the matching process. Such a deeper look at the sources of asymmetric dynamics on the labor market is left to future research.

\section{Appendix}

In the case of $n=2$ there are four possible states: $\left(I_{t-1}=0, I_{t-2}=0\right),\left(I_{t-1}=\right.$ $\left.0, I_{t-2}=1\right),\left(I_{t-1}=1, I_{t-2}=0\right)$, and $\left(I_{t-1}=1, I_{t-2}=1\right)$ and accordingly also four steady-state initial probabilities $\pi_{i j}=P\left(I_{2}=i, I_{1}=j\right), i, j=0,1$. Define the transition probabilities $\lambda_{i j}, i, j=0,1$ as

$$
\begin{aligned}
& \lambda_{11}=P\left(I_{t}=1 \mid I_{t-1}=1, I_{t-2}=1\right) \\
& \lambda_{10}=P\left(I_{t}=1 \mid I_{t-1}=1, I_{t-2}=0\right) \\
& \lambda_{01}=P\left(I_{t}=0 \mid I_{t-1}=0, I_{t-2}=1\right) \\
& \lambda_{00}=P\left(I_{t}=0 \mid I_{t-1}=0, I_{t-2}=0\right)
\end{aligned}
$$

and collect them into a vector $\boldsymbol{\lambda}^{(2)}=\left(\lambda_{11}, \lambda_{10}, \lambda_{01}, \lambda_{00}\right)^{\prime}$. In addition, define the numbers of transitions

$$
\begin{aligned}
& n_{i j}:=\sum_{t=3}^{T} 1_{\left\{I_{t}=i \wedge I_{t-1}=i \wedge I_{t-2}=j\right\}} \\
& \bar{n}_{i j}:=\sum_{t=3}^{T} 1_{\left\{\neg\left(I_{t}=i\right) \wedge I_{t-1}=i \wedge I_{t-2}=j\right\}} \quad, i, j=0,1 .
\end{aligned}
$$

Using these definitions, the log-likelihood for the sample $I^{T}=\left(I_{1}, \ldots, I_{T}\right)$ is

$$
\begin{aligned}
l\left(\boldsymbol{\lambda}^{(2)} ; I_{T}\right)=\log \pi_{i j}\left(\boldsymbol{\lambda}^{(2)}\right)+n_{11} \log \lambda_{11}+ & \bar{n}_{11} \log \left(1-\lambda_{11}\right)+n_{10} \log \lambda_{10} \\
+ & \bar{n}_{10} \log \left(1-\lambda_{10}\right)+n_{01} \log \lambda_{01}+\bar{n}_{01} \log \left(1-\lambda_{01}\right) \\
& +n_{00} \log \lambda_{00}+\bar{n}_{00} \log \left(1-\lambda_{00}\right)
\end{aligned}
$$

where $\pi_{i j}$ is the appropriate expression for the initial probability given the realizations $I_{1}$ and $I_{2}$.

In order to obtain expressions for the steady-state initial probabilities $\pi_{i j}$ define a vector of state probabilities $\boldsymbol{\pi}_{t}=\left(\pi_{11, t}, \pi_{10, t}, \pi_{01, t}, \pi_{00, t}\right)$. For the elements of $\boldsymbol{\pi}_{t}$ decompositions into the $\lambda_{i j}$ and $\pi_{i j, t-1}$ similar to those in (9) and (10) can be 
found. Defining the matrix

$$
A=\left(\begin{array}{cccc}
\lambda_{11} & \lambda_{10} & 0 & 0 \\
0 & \left(1-\lambda_{01}\right) & 0 & \left(1-\lambda_{00}\right) \\
\left(1-\lambda_{11}\right) & \left(1-\lambda_{10}\right) & 0 & 0 \\
0 & 0 & \lambda_{01} & \lambda_{00}
\end{array}\right)
$$

we have

$$
\boldsymbol{\pi}_{t}=A \boldsymbol{\pi}_{t-1} .
$$

In equilibrium, $\boldsymbol{\pi}_{t}=\boldsymbol{\pi}_{t-1}=\boldsymbol{\pi}$, so that

$$
(I-A) \pi=0 .
$$

The matrix $I-A$ has only rank 3 , but together with the condition $\pi_{11}+\pi_{10}+$ $\pi_{01}+\pi_{00}=1$ one obtains unique solutions for the steady-state initial probabilities. With the definition $D:=\left(1-\lambda_{00}\right)\left(1-\lambda_{11}+\lambda_{10}\right)+\left(1-\lambda_{11}\right)\left(1-\lambda_{00}+\lambda_{01}\right)$ we get

$$
\begin{aligned}
& \pi_{11}=\frac{\left(1-\lambda_{00}\right) \lambda_{10}}{N}, \\
& \pi_{10}=\frac{\left(1-\lambda_{00}\right)\left(1-\lambda_{11}\right)}{N}, \\
& \pi_{01}^{*}=\pi_{10}, \\
& \pi_{00}=\frac{\left(1-\lambda_{11}\right) \lambda_{01}}{N} .
\end{aligned}
$$

\section{References}

Anderson, Theodore W. and Leo A. Goodman, "Statistical Inference About Markov Chains," Annals of Mathematical Statistics, August 1997, 28, 89-110.

Cross, Rod, ed., Unemployment, Hysteresis and the Natural Rate Hypothesis Basil Blackwell Oxford 1988.

, ed., The Natural Rate of Unemployment - Reflections on 25 Years of the Hypothesis Cambridge University Press Cambridge 1995.

DeLong, J. Bradford and Lawrence H. Summers, "Are Business Cycles Symmetrical?," in Robert J. Gordon, ed., The American Business Cycle, University of Chikago Press Chikago 1986, pp. 166-179.

Escribano, Alvaro and Gerard A. Pfann, "Non-Linear Error Correction, Asymmetric Adjustment and Cointegration," Economic Modelling, 1998, 15 (2), 197-216. 
Falk, Barry, "Further Evidence on the Asymmetric Behavior of Economic Time Series over the Business Cycle," Journal of Political Economy, 1986, 94 (5), 1096-1109.

Garibaldi, Pietro, "The Asymmetric Effects of Monetary Policy on Job Creation and Destruction," IMF Staff Papers, 1997, 44 (4), 557-584.

Granger, Clive W. J. and Timo Teräsvirta, Modelling Nonlinear Economic Relationships, Oxford: Oxford University Press, 1993.

Hamermesh, Daniel S., "Spatial and Temporal Aggregation in the Dynamics of Labor Demand," NBER Working Paper No. 40551992.

, Labor Demand, Princeton: Princeton University Press, 1993.

Hamilton, James D., "State-Space Models," in Robert F. Engle and Daniel L. McFadden, eds., Handbook of Econometrics, Vol. 4, Amsterdam: Elsevier, 1994, chapter 50, pp. 3039-3080.

Hodrick, Robert J. and Edward C. Prescott, "Postwar U.S. Business Cycles: An Empirical Investigation," Journal of Money, Credit, and Banking, 1997, 29 (1), 1-16.

Kandil, Magda, "Demand-Side Stabilisation Policies: What is the Evidence of their Potential?," IMF Working Paper, Dezember 2000, (00/97).

MacKinnon, James G., "Critical Values for Cointegration Tests," in Robert F. Engle and Clive W. J. Granger, eds., Long-Run Economic Relationships, Oxford: Oxford University Press, 1991, pp. 267-276.

Mortensen, Dale T. and Christopher A. Pissarides, "Job Creation and Job Destruction in the Theory of Unemployment," Review of Economic Studies, 1994, 61 (3), 397-415.

Neftçi, Salih A., "Are Economic Time Series Asymmetric over the Business Cycle?," Journal of Political Economy, 1984, 92 (2), 307-328.

Nickell, Stephen, "Unemployment: Questions and some Answers," Economic Journal, 1998, 108 (448), 802-816.

Palm, Franz C. and Gerard A. Pfann, "Asymmetric Adjustment Costs in Non-Linear Labour Demand Models for the Netherlands and U.K. Manufacturing Sectors," Review of Economic Studies, 1993, 60 (2), 397-412.

and __ , "Sources of Asymmetry in Production Factor Dynamics," Journal of Econometrics, 1997, 82 (2), 361-392. 
Pfann, Gerard A., Dynamic Modelling of Stochastic Demand for Manufacturing Employment Lecture Notes in Economics and Mathematical Systems, Berlin: Springer, 1990.

__ , "Factor Demand Models with Nonlinear Short-Run Fluctuations," Journal of Economic Dynamics and Control, 1996, 20 (1-3), 315-331.

Pissarides, Christopher A., Equilibrium Unemployment Theory, 2 ed., Cambridge, MA: MIT Press, 2000.

Ramsey, James B. and Philip Rothman, "Time Irreversibility and Business Cycle Asymmetry," Journal of Money, Credit, and Banking, 1996, 28 (1), $1-21$.

Richardson, Matthew, "Temporary Components of Stock Prices: A Skeptic's View," Journal of Business \& Economic Statistics, April 1993, 11 (2), 199207.

Rothman, Philip, "Further Evidence on the Asymmetric Behavior of Unemployment Rates over the Business Cycle," Journal of Macroeconomics, 1991, 13 (2), 291-298.

Sichel, Daniel E., "Business Cycle Asymmetry: A Deeper Look," Economic Inquiry, 1993, 31 (2), 224-236.

Tong, Howell, Non-Linear Time Series - a Dynamical System Approach, Oxford: Clarendon Press, 1990. 


\section{IZA Discussion Papers}

$\begin{array}{ll}\text { No. } & \text { Author(s) } \\ 260 & \begin{array}{l}\text { P. Cahuc } \\ \text { F. Postel-Vinay }\end{array} \\ 261 & \text { M. Lindahl }\end{array}$ Communism: Some Empirical Evidence 

A. Kaul
M. Kolmar

Efficiency Properties of Labor Taxation in a 

and the Rising Returns to Skill: US and France 1964-2000 

H. Bonin
G. Abío
E. Berenguer
J. Gil
C. Patxot

307

G. A. Pfann

308

G. A. Pfann

D. S. Hamermesh

309
G. Brunello

310

U. Sunde

M. Kemler

G. A. Pfann 

A. Frederiksen
E. K. Graversen
N. Smith

Germany: The Impact on Productivity and Wages Model 
Why Do Firms Recruit Internationally? Results Quality
A. lbourk
B. Maillard
S. Perelman
H. R. Sneessens

The Matching Efficiency of Regional Labour Markets: A Stochastic Production Frontier

Estimation, France 1990-1995 